\title{
Availability and Access to Support Services in a Blended Learning Environment
}

\author{
Samuel Amponsah, University of Ghana, Ghana \\ (iD) https://orcid.org/0000-0002-4303-4863 \\ Yvette Ussher, University of Ghana, Ghana \\ Kwesi Amoak Benjamin, University of Ghana, Ghana \\ (iD) https://orcid.org/0000-0003-0990-1174
}

\begin{abstract}
The transformation in the distance education system has led to the emergence of blended learning approaches that have necessitated effective support to facilitate students learning. This web survey aimed at determining the kinds of support available and accessible to distance education students of the University of Ghana. Data collected from 103 Levels 300 and 400 students and findings from the survey indicated that physical and technological support services were frequently used among the respondents, whereas residential and e-library resources were the least subscribed support services among the students. In terms of social support services, interaction with tutors and interaction with fellow students came up as the main support services available to students while counselling services were absent for these students. It was recommended that the support services that were inadequate, least used, and absent should be provided to enable students to complete their programmes of study successfully.
\end{abstract}

\section{KEYWORDS}

Blended Learning, Flipped Classroom, Hybrid, Learning Environment, Sakai Learning Management System, Support Services, Technology

\section{INTRODUCTION}

The upsurge of digital technologies has led to dramatic reforms in education. These digital technologies have enabled the use of virtual spaces in addition to the traditional classroom environment (Papadakis, Kalogiannakis, Sifaki, \& Vidakis, 2018; Suorsa, 2014). Therefore there is a shift from solely problembased learning activities in the classroom as students can now communicate with their instructors digitally and access new materials, read and be prepared before coming to class (Papadakis et al, 2018; Amira et al; 2019). Consequently, this led to the vital role Information and Communication Technology (ICT)-based learning which has been distinguished by a higher level of student control and autonomy over time, place and pace through the delivery of instruction and content via digital 
and online media (Ansong, 2015). As a result, attention has shifted to blended learning which is also referred to as hybrid learning or at times flipping the classroom (Ansong, 2015; Sarfo \& Ansong-Gyimah, 2010; Lin \& Wang, 2012). Zhonggen (2016) categorised how blended learning has transcended the idea of classroom and learning activities supported by online technologies to the integration of learning, students and instructor activities made possible by both technology and traditional modes of transmission.

The increasing prominence and future prospects of blended learning could be due to the contemporary challenges of education such as the diversity of learners, cost and the need to achieve measurable outcomes. It may also be attributed to the propensity of evolving technologies for learning in this era while maintaining traditional and/or historical groundings and purpose of education (Bath \& Bourke, 2010; Rajkoomar \& Raju, 2016). As noted by Lalima and Dangwal (2017) as well as Pokuaa (2011), the increase in population, especially in developing countries and the need to find innovative ways of educating more people, naturally necessitates the incorporation of technology into the traditional classroom. It has also been established that the teeming masses of adult learners who aspire to acquire higher qualifications can only achieve their aspirations when online and digital learning tools are leveraged in higher institutions through blended learning pedagogical approaches.

The future, therefore, implies that for teaching and learning to be efficient, teachers and educational administrators must willy-nilly unlearn past attitudes, reform and create the best atmosphere and support for students (Barrett, 2010). For instance, Baytiyeh (2019) makes a strong case for the inclusion of mobile learning technologies in higher education learning which is escalated by Kumar and Nanda (2019) as the use of social media generally. In this way, students will learn effectively and be positioned to fit into the 21 st-century work environment. In the light of the foregone, it has been noted by Lock and Johnson (2016) that the widespread usage of blended learning has the propensity to influence change in higher education institutions in the short term. However, it is worth establishing that effective blended learning could be achieved through the provision and access to support services. This makes it imperative to student support units to serve its purpose by tailoring support services and systems to suit the socio-cultural needs of students.

\section{THE STUDY CONTEXT}

By way of background information, the University of Ghana's attempt to incorporate technology into the traditional means of transmitting knowledge, thus, making the university and its products compliant to $21^{\text {st }}$ century standards date back to 2010. However, the University Council approved the UG ICT Policy in March 2012, followed by the Business and Executive Committee sanctioning the Policies and Procedures on Technology-Mediated Courses and Programme in E-Learning (ICT Deployment Committee Report, 2014). The sanctioning of the documents provided a foundation for incorporating technology into traditional pedagogical approaches to content delivery in the university, paving the way for blended learning to be introduced.

As noted by Lalima and Dangwal (2017), population explosion, especially in developing countries, has necessitated innovative methods of making schools accessible to those who might not have gained access to brick and mortar schools. This assertion seems to have been a key factor in the introduction of blended learning at the University of Ghana as recorded in the ICT Deployment Committee's Report (2014) that successful implementation of e-learning in the DE programme will help increase student enrollment at the University. Additionally, the University's Chinese Phase I Project which commenced in 2009 and was leveraged to Phase II in 2010 aimed at providing the necessary infrastructure to support ICT-based teaching and learning. To achieve this, ICT facilities were installed in eight of the University's 11 learning centres (Awiah, 2015). This development is supported by Agbanu, Sonyo and Ahiase's (2018) argument that DE providers have expanded their learning environment from a limited geographical location to several other locations, termed satellite campuses or learning centres to make room for inclusivity and lifelong learning. 
In 2014 the UG ICT Project was finally inaugurated. This inauguration coincided with the launch of the Sakai Learning Management System (SLMS) which had been successfully piloted between 2010 and 2013 and received satisfactory reports. This gives credence to an assertion by Van Wyk (2018) that global trends in higher education have become more inclusive and blended based on the availability and usage of more digital pedagogies that support and accelerate student learning. In this regard, the ICT Deployment Committee had its focus on a bimodal approach to content delivery for the UGDE students, namely; Web-based (Fully Online) and Multi-Mode (Hybrid or Blended) (ICT Deployment Committee Report 2014). With regards to the blended mode, the report stated thus,

In a multi-mode course, online components of the courses would replace some of the regularly scheduled class meetings. A Tuesday-Thursday class, for instance, might meet one day in a week throughout the semester, with the remaining instruction taking place online using an LMS (p. 24).

The current researchers note that all the efforts put in by the university to incorporate technology into its system will amount to nothing if commensurate support systems are not put in place, especially for its students. Consequently, this paper aimed at determining the kinds of support offered in the University of Ghana blended environment and the extent to which these services are accessed by distance students enrolled at the said institution.

\section{LITERATURE REVIEW: SUPPORT IN A BLENDED MODE}

The ability of online learning to provide the needed support that enhances student learning has been questioned by researchers such as Zhou, Zhao, Jiang and Wang (2017). However, Graham (2006) cited in Wu, Tennyson and Hsia (2010) earlier argued that blended e-learning systems are capable of filling the void that full online learning environments cannot fill. It is in this direction that Gyamfi and Gyaase (2015) emphasized that student support is an integral aspect of blended learning and the extent of such support could enhance or mare the experience of learning in the blended environment. Similarly, Bridges (2008) asserted that student support services, such as academic tutorial, faculty and peer monitoring and counselling are critical to student success as they enable students to achieve the best of their years in college. In this regard, Gyamfi and Gyaase (2015) indicated that the provision of appropriate and adequate communication tools in blended learning enhances cooperative learning as students interact among themselves and with lecturers.

Admittedly, the provision of web-based materials, consistent with Zhou et al's, (2017) fivedimensional learning support service system for blended learning [see next section], becomes often indispensable. However, in countries, like Ghana, where internet infrastructure is still not fully developed and thus saddled with slow speed, interruptions in connectivity and lack of access at times, it becomes problematic to effectively implement blended learning. Additionally, it is important bearing in mind that the innovations in teaching and learning required by blended learning are only possible with a well-developed plan and necessary funding (Gyamfi \& Gyaase, 2015). It is, therefore, possible to raise the standards of education using the opportunities offered by a blended learning programme with appropriate content, tools and student support. This resonates in the assertion by Zhou et al. (2017, p.276) that 'a good learning support service system provides strong support for blended learning (p. 276). Annku (2014) has, in a similar direction, argued that there should be a conscious effort to incorporate blended learning concepts and methods in teacher education programmes in order to help teachers familiarise and master blended learning tools and models as part of their pre-service training.

Furthermore, it will be beneficial to accept that the spectrum of support services provided for DE students is so varied to the point that Simpson (2016) submitted it can be too large and complex to be covered in a single document. He, therefore, categorised student support for DE students, which are all relevant to the blended environment, as cognitive or academic support for enhancing students' learning and cognitive skills. The other broad category of support Simpson (2016) identified is non- 
academic support which encapsulates the organisational support and emotional support for learners. For Ling and Wang (2012), a plan for blended learning was demonstrated in rather practical terms. They looked at blended learning as the computer platform that serves as an interface between faceto-face interactions and e-learning that result in learning among students. The plan by Lin and Wang (2012) is indicative that blended learning does not happen in a vacuum. Hence, effective planning will eventually lead to learning in the face of the provision of support for the students engaged in the blended learning space.

\section{THEORETICAL MODEL: FIVE-DIMENSIONAL LEARNING SUPPORT SERVICE SYSTEMS OF BLENDED LEARNING}

Literature abounds on support systems for traditional DE and online learning but the same cannot be said for blended learning. This is corroborated by an argument by Wu et al. (2010) that there is the lack of studies that establish student satisfaction in the blended e-learning environment which was endorsed by Zhou et al. (2017) seven years down the line. This gap is indicative that not much has been done in terms of developing an independent theory for understanding student support in the blended environment. That notwithstanding, Zhou et al's. (2017) five-dimensional learning support service system of blended learning (presented as Figure 1 below), is seen as a model that can effectively be used to gauge the effectiveness of support provided for students at the UG blended learning landscape.

It can be noted from figure 1 that each of the five dimensions in the model has been sub-categorised into what will enhance student support in the blended learning environment. For instance, with the resource support service dimension, Zhou et al. (2017) identified the need to mix digital media with traditional ones such as books and objects to provide support for students. This form of support finds meaning in Simpson's (2016) cognitive/academic support, which seeks to bring about quality teaching, develop students' learning skills and ensure assessment and feedback.

Secondly, the platform support services dimension throws light on the need to provide virtual simulation labs and networked teaching and learning platforms for teaching and learning and feedback. Simpson (2016) discussed emotional support as a way of helping students deal with the emotional side of learning. He advocated for ways of developing learner motivation, self-confidence and ways of managing stress with special emphasis on assessments. With regard to the UGDE programme, the face-to-face tutorials can substitute platform support while the interactive tools on the Sakai LMS and other social media tools may help in providing the same in the virtual environment.

Furthermore, the teaching method support services is another dimension of the model under discussion. It seeks to bring about both online learning and face-to-face learning as witnessed in the UGDE programme (ICT Deployment Committee Report, 2014). This dimension reflects the cognitive/ academic support espoused by Simpson (2016) and face-to-face and e-learning aspects of Lin and Wang's (2012) plan for blended learning. Effective utilisation of this dimension brings to light the idea of a flipped classroom where students stand the chance of accessing materials and resources on the online environment prior to face-to-face meetings.

The next dimension, that is, personnel support services, seeks to encourage the participation of all players in the blended environment. Zhou et al. (2017) have indicated that this dimension is the core of the learning support service in blended learning. This dimension can be categorised as Simpson's (2016) academic support if the essence is to help students succeed in their studies directly. On the other hand, if they seek to provide organisational or emotional support then it can be placed under the non-academic support category.

Finally, the environmental support services dimension, which basically delves into the teaching and learning environment, interfaces the classroom environment with the network environment. This dimension is also consistent with Lin and Wang's (2012) plan for blended learning whereby they advocated for the combination of face to face learning and e-learning in the blended environment. Zhou et al. (2017, p. 273).) noted thus, 'the mixture of the network learning environment and the 


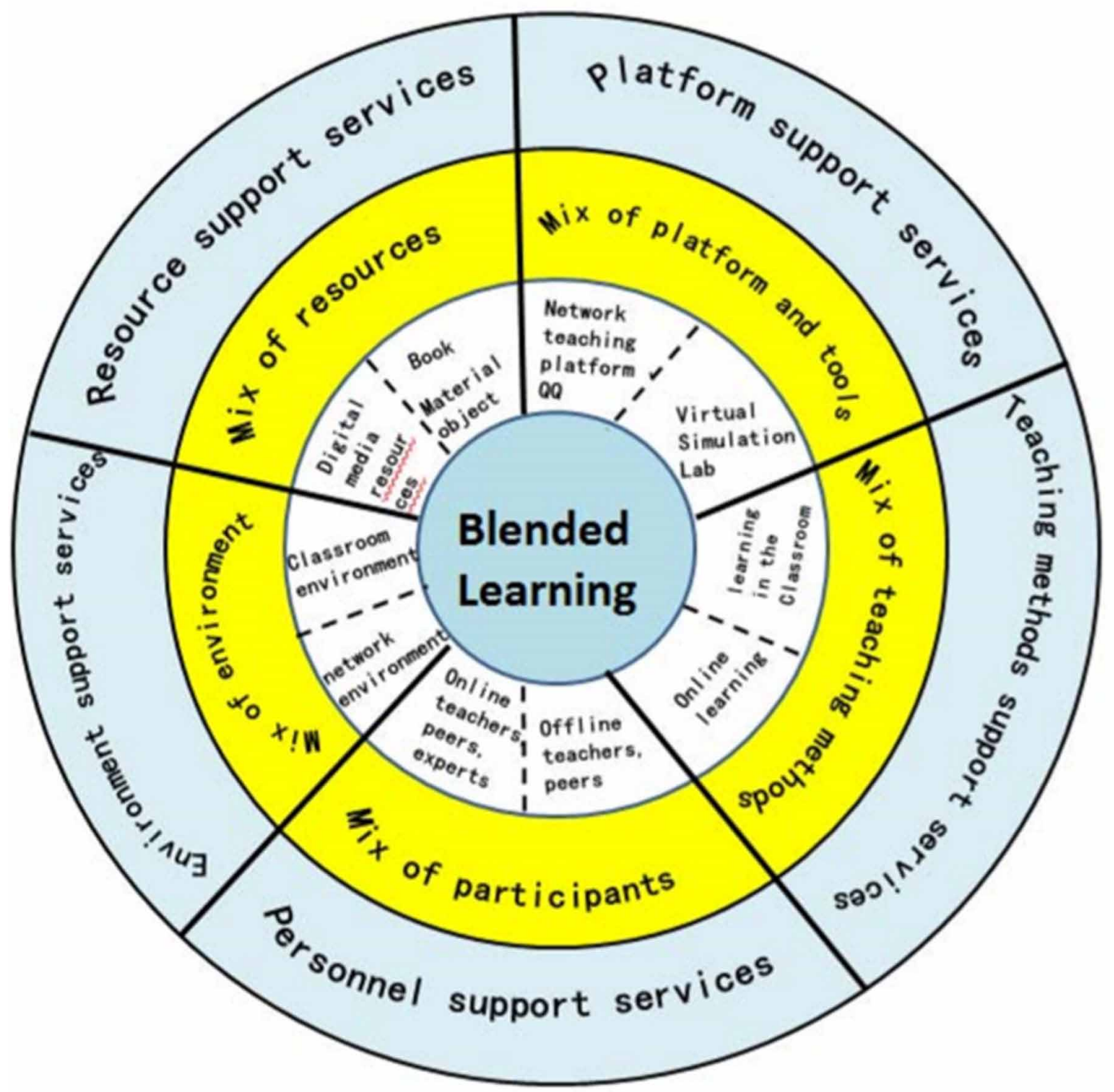

classroom environment makes the whole blended learning environment an organic whole' Essentially, a good learning environment is imperative in the development of an effective blended learning environment. Especially, in Ghana where technology still remains a luxury for many who would still want to pursue higher education.

In a nutshell, it is worth noting that Zhou et al's (2017) model stands out as one that seamlessly brings together the key constructs that serve as support systems for students learning in the blended environment. In specific terms, the adoption of the Sakai LMS by the University of Ghana to provide blended learning puts the University at the forefront of $21^{\text {st }}$ century-based knowledge and skills in Ghana and many other African countries. For this reason, Zhou et al's model is regarded as a one that can help explore the availability and access to the support services provided and accessible in the UG blended landscape. 


\section{METHODOLOGY}

The study adopted a quantitative cross-sectional design in the form of a web-survey. The design was deemed appropriate as it analyzes data from a representative subset of a population at a specific point in time and makes inferences about that population. Our initial sampling was done focusing on the stratified sampling method, from all students on the University of Ghana Distance Education (UGDE) programme totalling 9,311. Based on academic levels, a sample of 380 students in the third and final (Level 300 and 400) years were selected from all the eleven learning centres of the UGDE programme, using Krejcie and Morgan's (1970) ${ }^{1}$ sample size determination method. Focus then fell on the third (Level 300) and final year (Level 400) BSc Nursing students and BSC Information Technology students in all the learning centres, selecting 190 of them. These respondents were chosen as they were students who have gone through the system for at least three years and have the requisite knowledge of the support services available and accessible towards the success of their studies.

Data was gathered through an online questionnaire consisting of 40 items which include 33 closed and seven open-ended questions. The questionnaire was split into three sections: a) biographic data of respondents (e.g. age, sex, and entry qualification), b) frequency of use of physical and technological support and c) availability and frequency of use of social support services. The questionnaire was pretested for reliability and validity with 12 distance education students (Level 200 and 300) from the various learning centres. The pretesting was done in July 2018 when students were on the University of Ghana campus to write their first semester examinations. Results were analyzed to determine reliability using Cronbach's alpha method and obtained 0.79, indicating that the questionnaire has acceptable substance. The finalized instrument was then developed using a Google form. Hence the study employed a web-survey and administered the questionnaire via the web. The preamble of the finalized questionnaire assured confidentiality of responses and anonymity, as well participation in the study is voluntary and one could withdraw at any time and not obliged to respond to questions one feels uncomfortable with

Respondents were recruited via their WhatsApp platforms by sending the link of the questionnaire to them. The class representatives were contacted, and the web link was forwarded to the class representatives who in turn put it on their respective class WhatsApp group platforms. Reminders were sent on a daily basis on the platforms by the class representatives and researchers for students to complete the questionnaire. Data was collected between August and September 2018 after students had completed their semester examinations. In all, a total of 103 responses were received after eight weeks of frequent reminders by the course representatives and researchers. The data were analyzed using SPSS version 22. The data was analyzed using both descriptive and inferential statistics specifically frequency tables, cross-tabulation and chi-square test of significance.

\section{RESULTS}

This section presents the results that emanated from the analysis of the results. It is presented in descriptive statistics.

\subsection{Demographic Characteristics of Respondents}

It was noted that out of a total respondent of 103 in this study, majority (78.7\%) were females while the male representation was only $22.3 \%$. It was also evidence that majority of the respondent $(51.5 \%)$ was within the ages of $21-30$, while $44.7 \%$ were within the ages of $31-40$. Only $3.8 \%$ of respondents were below 20 years which signifies that a large majority of the UGDE students are young. The BSc Nursing students dominated (83.5\%) the respondents of the study with a majority $(82.5 \%)$ of them entering the UGDE programme using their diploma certificates. This is expected, as the professional nurses are admitted into this programme and most of them already possess diploma in nursing certificates from the colleges that trained them. 
Table 1. Frequency of use of physical and technological support services

\begin{tabular}{|l|l|l|l|l|}
\hline \multirow{2}{*}{ Physical/Technical Support Services } & Frequently & Occasionally & \multicolumn{1}{c|}{ Rarely } & \multicolumn{1}{c|}{ Not at all } \\
\cline { 2 - 5 } & \multicolumn{1}{|c|}{$\boldsymbol{f}(\%)$} & \multicolumn{1}{c|}{$\boldsymbol{f}(\%)$} & $\boldsymbol{f}(\%)$ \\
\hline Video conferencing & $29(28.2)$ & $40(38.8)$ & $22(21.4)$ & $7(6.8)$ \\
\hline Tele conferencing & $14(13.6)$ & $13(12.6)$ & $29(28.1)$ & $42(40.8)$ \\
\hline Emails with tutors & $29(28)$. & $26(25.2)$ & $34(33.0)$ & $11(10.7)$ \\
\hline Interacting with colleagues online & $47(45.6)$ & $22(21.4)$ & $21(20.4)$ & $8(7.8)$ \\
\hline Revision & $52(50.5)$ & $26(25.2)$ & $18(17.5)$ & $3(2.9)$ \\
\hline e-library resources & $18(17.5)$ & $39(37.9)$ & $27(26.3)$ & $13(12.6)$ \\
\hline Online learning tools & $38(36.9)$ & $23(22.3)$ & $23(22.3)$ & $13(12.6)$ \\
\hline Face to face tutorials & $56(54.4)$ & $17(16.5)$ & $17(16.5)$ & $12(11.7)$ \\
\hline library services/ resources & $24(23.3)$ & $33(32.0)$ & $32(31.1)$ & $8(7.8)$ \\
\hline lecture halls & $52(50.4)$ & $21(20.4)$ & $19(18.4)$ & $7(6.8)$ \\
\hline written materials/ modules & $42(40.8)$ & $21(20.4)$ & $23(22.4)$ & $12(11.7)$ \\
\hline Residential Facility & $6(5.9)$ & $8(7.8)$ & $16(15.5)$ & $64(62.1)$ \\
\hline
\end{tabular}

$N=103$

Even though respondents were expected from all the eleven (11) University of Ghana learning centres across Ghana, only students from three of the centres participated in the study. A majority (92.7\%) of the respondents studies at the Accra Learning Centre, followed by Tsito Learning Centre (3.9\%) and Tamale Learning Centre (2.9\%). This is not surprising since Accra has the largest student population with a relatively reliable internet connection and stable electricity compared to the other centres.

\subsection{Frequency of Use of Physical and Technological Support Services}

Zhou et al. (2017) developed a five-dimensional model that establishes the importance of support systems in a blended learning environment. This is indicative that support in the blended space is a two-pronged affair. As such, institutions ought to provide the necessary support systems while students subscribe or access such services. In light of the foregoing, Table 1 shows the physical and technological support service availability and frequency of use among UGDE students.

Due to its availability and easier accessibility, the frequently used physical and technological support service is face to face tutorials (54.4\%). It is quite interesting that face-to-face tutorials are predominantly used among these students, which suggests that even though they are DE students, coming to the campus adds to their prestige as University of Ghana students. Even though available video conferencing were occasionally used by UGDE students.

A key ingredient for blended learning is e-library services leading to the University of Ghana to make provision of e-library services for these students; however, they tend to occasionally use these services indicating that even though they are DE students and use the blended mode, they may not yet be conversant with online library services and resources available at their campuses and even the main campus. They may also not have time to visit the library as they are mostly engaged with their work and social activities.

One main characteristic of distance education students is to liaise with instructors and tutors online. Surprisingly, it was noted that rarely do these students email their tutors (33\%) or interact with them online. Students were not doing so because of unavailability and access to tutors' email addresses. It was not surprising that majority (62.1\%) of the students never have access to or used 
residential facilities. This is because such facilities have not been made available and accessible to the distance students.

\subsection{Expected Physical and Technological Support Services}

To further explore availability and access to physical and technological support services students were asked to mention at least three major services they expected to be provided for their studies. A majority (90\%) of them expected support services in the form of learning materials (examples, hardcopy modules and pre-recorded videos), face to face lectures and provision of tablets. Having practical sessions and demonstrations in a laboratory featured as physical services expected by the nursing students.

The participants indicated that the lack of such expected services have affected their learning as the majority (90\%) of students argued that they are not able to easily comprehend some of the online modules provided. This coupled with the absence of face to face sessions with tutors instead of lecturers diminished their sense of belongings to the university. To enhance their learning and feel some sense of belongingness, the students revealed that they have created WhatsApp group platforms and group discussion platforms which they felt provided them with the support they needed in their studies. They also indicated that the Sakai LMS chat room facility also aided their learning as they interacted and discussed issues on the platform. Additionally, their own face to face group discussions helped them to clarify and revise concepts and theories learnt. Such support services provided by the students explain why there are frequent interactions with their course mates (see table 1). Also, it reflects an element of peer learning and online cooperative learning covered under personal support in Zhou et al's (2017) five-dimensional model.

\subsection{Demographic Characteristics and Determinacy of Support Service Accessed}

To determine whether there is a relationship between the socio-demographic background (sex, age, programme and level of study) of students and support services accessed to ascertain its significance, we used cross-tabulation and did chi-square to test the significant relationship between the demographic background (sex, age, programme and level of study) of students and support services accessed, the findings are shown in table 2.

Table 2. Demographic characteristics and determinacy of support service accessed

\begin{tabular}{|l|l|l|l|l|}
\hline \multicolumn{1}{|c|}{ Support Services } & \multicolumn{1}{c|}{ Sex } & \multicolumn{1}{c|}{ Age } & \multicolumn{1}{c|}{ Prog. S. } & Lev. S. \\
\hline Video conferencing & .000 & .001 & .000 & .571 \\
\hline Tele conferencing & .000 & .000 & .001 & .886 \\
\hline Emails with tutors & .000 & .002 & .000 & .015 \\
\hline Interacting with colleagues online & .000 & .000 & .000 & .004 \\
\hline Revision & .000 & .002 & .000 & .000 \\
\hline e-library resources & & .074 & .001 & .755 \\
\hline Online learning tools & .000 & .100 & .010 & .009 \\
\hline Face to face tutorials & .000 & .000 & .001 & .086 \\
\hline library services/ resources & .000 & .075 & .007 & .898 \\
\hline lecture halls & .000 & .001 & .000 & .269 \\
\hline Written materials/ modules & .000 & .010 & .001 & .370 \\
\hline Residential Facility & .004 & .327 & .000 & .995 \\
\hline
\end{tabular}

$\mathrm{N}=103$ 
Table 3. Frequency of use of social support service

\begin{tabular}{|l|c|c|c|c|}
\hline \multicolumn{1}{|c|}{ Social Support services } & High & Moderate & Low & Not at all \\
\cline { 2 - 5 } & $\boldsymbol{f ( \% )}$ & $\boldsymbol{f ( \% )}$ & $\boldsymbol{f}(\%)$ & $\boldsymbol{f}(\%)$ \\
\hline Interactions with tutors & $8(7.8)$ & $42(40.8)$ & $36(35.0)$ & $9(8.7)$ \\
\hline Interactions with students & $39(37.9)$ & $34(33.0)$ & $18(17.5)$ & $4(3.9)$ \\
\hline Interactions with staff & $4(3.9)$ & $37(35.9)$ & $44(42.7)$ & $10(9.7)$ \\
\hline Tutors' email addresses & $23(22.3)$ & $37(35.9)$ & $30(29.1)$ & $5(4.9)$ \\
\hline Staffs' email addresses & $2(1.9)$ & $27(26.2)$ & $57(55.3)$ & $9(8.7)$ \\
\hline Colleagues email addresses & $22(21.4)$ & $29(28.2)$ & $32(31.1)$ & $12(11.7)$ \\
\hline Contact numbers for support & $6(5.8)$ & $27(26.2)$ & $47(45.6)$ & $13(12.6)$ \\
\hline Information desk/ call centre & $6(5.8)$ & $40(38.8)$ & $38(36.9)$ & $11(10.7)$ \\
\hline Counseling services & $1(1.0)$ & $15(14.6)$ & $54(52.4)$ & $25(24.3$ \\
\hline
\end{tabular}

$\mathrm{N}=103$

The computed chi-square results (with a $p$-value $<05$ ) in Table 2 shows that there was a strong significant relationship (with a p-value .05 ) between sex as well as the programme of study with all the physical and technological support services listed. In the same vein, there was a significant relationship between age and all the listed support services except in the case of accessing e-library and library resource as well as a residential facility where there was no statistically significant relationship. Quite interestingly, a significant relationship (with a $p$-value ${ }^{>} .05$ ) exists between the level of study and interaction with colleagues, revision and use of online tools. These results, therefore, suggest that sex, age and programme of study play a significant role in the usage of physical and technological support services listed among UGDE students. In other words, the findings indicate that accessing the listed support services is determined by sex and age as well as the programme of study.

\subsection{Frequency Use and Availability of Social Support Service}

In exploring social support services accessed and used by UGDE students, the results established quite varied views. These views reflect in table 3 with detailed explanations following.

It is clear from table 3 that interaction with students' colleagues is very high (37.9\%) whereas students' interaction with tutors, $(40.8 \%)$ was quite moderate. The moderate interaction with tutors is as a result of inaccessibility of tutors beyond the tutorial sessions and the contact numbers and email addresses not readily provided to the students. The high interaction with students and their colleagues is due to the WhatsApp group platforms they have created allowing for the group discussion as well as the use of the Sakai LMS chat room tool to aid their learning.

It was also noted that the lack of access to [administrative] staff email for any support services needed led to the low interaction (55.3\%) as students argued that such email addresses were not made available to them. The findings also indicated that there was none utilization of counselling services (52.4\%) which could be attributed to the lack of knowledge of such services and students mistrust and unreadiness to share their challenges with third parties who could come to their aid or facilitate their distance learning journey.

\section{DISCUSSION OF FINDINGS}

This study was aimed at identifying the kind of support provided for students in the UGDE blended environment and to establish the accessibility of such support. Findings showed that the predominant support service available and frequently accessed by UGDE students is face to face tutorials. The 
availability of this support service leads to oversubscription of face-to-face tutorials which is skewed towards the traditional side of Zhou et al's (2017) five-dimensional learning support model, which is specifically environmental in nature. The study also found that majority of the students (90\%) expected support services in the traditional form, that is resource support service such as learning materials/modules, pre-recorded videos, in addition to environmental support in the form of face-toface interaction with lecturers and provision of quality tablets to enable students to join the virtual learning environment. Two things pun out based on the findings so far; the university has not been able to orient the students on the more sophisticated forms of distance education support services with regards to the flipped classroom hence students are fixated to the predominantly traditional forms of support. This provides a premise that makes Zhou et al's (2017) model an indispensable and critical tool in planning and offering the right kind of support for students in a blended landscape.

One key component of Zhou et al's (2017) five support service dimensions, platform support service, was noted to be unavailable and inaccessible for UGDE students. The e-library services meant to be an integral component of the UGDE programme as a reflection of the ICT Deployment Committee Report (2014) in Ghana was absent. Unfortunately, this key support service component has not been fulfilled and may largely owe to poor internet infrastructure, network challenges and the capital-intensive nature of providing such modern facilities in a developing country like Ghana. For the DE blended learning model to be effective and impactful, there is the need to plan appropriately, invest in these vital support services (platform) and made available and easily accessible to students (Gyamfi \& Gyaase, 2015).

Another finding also suggested that students' interaction with lecturers and tutors on both faceto-face and online environments is not encouraging. As a result, students would have preferred their courses to be tutored by the lecturers themselves in order to have more contact with these lecturers. In essence, the kind of support advocated by Bridges (2008), Gyamfi and Gyaase (2015) as well as the teaching method, personal and environmental support services advocated by Zhou et al's. (2017) model is not available for the UGDE students. The absence of these services tends to make the most UGDE students, feel sidelined because they are not able to access so many facilities that mainstream students access on the university campus. It is therefore imperative that any form of pedagogical distance is dealt with effectively by connecting these students with their respective course lecturers by providing them with the necessary support needed for an effective flipped classroom environment. Such provision would lead to collaborative learning, reflecting a true picture of students involved in the blended learning mode.

Furthermore, we found out that collaborative learning in the virtual learning environment is not encouraging as interactions between colleague students on the Sakai LMS is not high and frequent (as represented by $37.9 \%$ of the responses obtained). Although not used frequently, the chat room tool of Sakai LMS appeared to be one of the platforms that aided students' learning as they interact with each other and discuss issues. In order to aid their learning and be more effective, the students have created WhatsApp group platforms and small group discussion platforms which they feel are additional environment and teaching method support services. Through the face to face group discussions, they are able to clarify and revise concepts and theories learnt. In this way, the students have filled in the gap by bringing into place the support systems that Bridges (2008), Gyamfi and Gyaase (2015) and Zhou et al. (2017) have advocated for. Irrespective of the students' ages and background, they belong to the cohort of $21^{\text {st }}$-century learners and have gone ahead to fill in the void that the university has not yet filled. Through social media tools, they are able to connect and support themselves in their studies. This kind of engagement by the students resonates calls by researchers to incorporate mobile learning technologies and social media tools into higher education learning (Baytiyeh, 2019; Kumar $\&$ Nanda, 2019). This is a clarion call for the university to fulfil its mandate fully by balancing the kind of support provided for students in the blended learning environment.

This study also established that there have not been adequate counselling support services (i.e. personnel support) extended to DE students who may have peculiar challenges such as stress, academic 
pressure, family and work-related issues in the light of undertaking an academic programme by distance. This situation is given prominence as the finding of this study established that counselling services were lowly rated with more than half $(52.4 \%)$ of the respondents never having access to counselling service during their at least three years of studies through the blended learning mode. Although this could be attributed to the inadequate knowledge of students on the counselling services rendered by the University, other factors, such as making such service accessible, the location of the counselling centres (main University campus), mistrust of counsellors and student's orientation to counselling could be some of the reasons why they do not access counselling services. Additionally, these students go to their respective study centres on weekends and the counselling centres operate during the weekdays, hence, their unavailability to the DE students. Consequently, if students are to survive in the blended learning environment, the typologies of students support systems elements in Zhou et al's. 2017 five-dimension model must be equally provided for all calibre of students in higher education institutions. On the other side, students should access and take full advantage of all support services available to lessen their load in the DE environment.

\section{CONCLUSION}

Theorists such as Bridges, Simpson, van Wyk and Zhou et al. have advocated for the provision of student support for learners, especially, those in the online and blended domain. Consequently, the University of Ghana rolled out an ambitious plan in 2014 to ensure that through the use of ICT tools, the hybrid or blended modes are adopted for teaching and learning. However, it was established in this study that majority of the UGDE students subscribe to the traditional forms of support at the expense of the online equivalents by virtue of the fact that the traditional support systems are readily available and are easily accessible to the students. Based on the innovative nature of students, those in this study had resorted to setting up WhatsApp groups and small group discussions platforms to compensate for the interactions they missed from their lecturers and tutors. The environment and teaching method support services created help students to enhance their learning as they discuss and deliberate on issues difficult to understand on their own facilitated collaborative learning and bridged the pedagogical distance among them. Collaborative learning as one of the key components of blended learning needs the input and active participation of tutors, lecturers and students. There is, therefore, no gainsaying that in the delivery of lessons, tutors and lecturers must be adequately skilled to facilitate/navigate the cooperative online learning environment with students in an efficient manner. This assertion finds its roots in the three typologies of support (cognitive or academic, cognitive skills and non-academic) established by Simpson. Ultimately, learning is an interactive process between teachers and students. The process should therefore not end after the face-to-face sessions for DE students to be left to their fate without responding to their emails for clarification and expression of concerns. In this regard, tutors need to be regularly assessed, mentored and trained to be effective in their delivery of online support to DE students, for without expertise, blended learning may not yield the expected outcomes.

Of much importance also is the students' inability to access counselling services in almost their entire years of study on the UGDE programme; a situation that might compound the stress and difficulties they face as distance students. Attention should, therefore, be paid to this unavailable and unaccessible support service as the five dimensions of support services outlined by Zhou et al. are mutually inclusive to enable blended learning programmes to assume a holistic outlook. An omission in the provision of one vital support service is inimical to UGDE students' performance and appreciation of the blended learning mode in a country like Ghana as a whole.

In a nutshell, this study has explored a grey area in the Ghanaian context as far as the blended learning environment is concerned. Many studies have delved into student support among mainstream and DE students but this study has ventured into support in a blended environment making use of theoretical model specifically developed for such environments. Based on the findings from this study, 
we recommend that all the support services that are either not available or inaccessible, especially those that skew towards technology, should be provided or leveraged in order to fully support students in such environments to succeed. Also, efforts should be made to orient both students, lecturers, tutors and administrative staff in such environments to be fully abreast with the exigencies on the ground so they will acquire the full understanding, necessary skills and the attitude to make support services available and accessible to students. On a larger scale, policymakers should implement policies that will engender institutions providing learning in the blended environment to ensure they provide and make accessible all forms of support to their students. Lastly, elements of the five-dimensional learning support system, expounded by Zhou et al. could be considered by all stakeholders in the blended learning environment as holistic and ride on its back to ensure equity in the provision of support services for DE students. All said and done, this study has set the tone for a longitudinal study on the phenomenon for a specific cohort of DE students. We also recommend a full qualitative study with different stakeholders to delve deeper into the phenomenon. 


\section{REFERENCES}

Agbanu, G., Sonyo, E., \& Ahiase, G. (2018). Examining factors influencing student satisfaction in distance education in Ghana: a study of the institute for educational development and extension, University of Education, Winneba. The Online Journal of Distance Education and e-Learning, 6(1), 33-44.

Amira, T., Lamia, M., \& Hafidi, M. (2019). Implementation and Evaluation of Flipped Algorithmic Class. International Journal of Information and Communication Technology Education, 15(1), 1-12. doi:10.4018/ IJICTE.2019010101

Annku, E. (2014). Technology-enhanced teaching and learning: A case of the faculty of art in Kwame Nkrumah University of Science and Technology [Unpublished MPhil Thesis]. Kwame Nkrumah University of Science and Technology.

Ansong, E. (2015). Determinants of e-learning adoption in universities: Evidence from a developing country (MPhil Thesis). University of Ghana Business School.

Awiah, D. M. (2015). University of Ghana inaugurates ICT project. https://www.graphic.com.gh/news/generalnews/university-of-ghana-inaugurates-ict-project.html

Barrett, B. (2010). Virtual teaching and strategies: Transitioning from teaching traditional classes to online classes. Contemporary Issues in Education Research, 3(12), 17-20. doi:10.19030/cier.v3i12.919

Bath, D., \& Bourke, J. (2010). Getting started with blended learning. Griffith Institute for Higher Education.

Baytiyeh, H. (2019). Mobile learning technologies as a means of maintaining education delivery in crisis situations. International Journal of Information and Communication Technology Education, 15(3), 1-10. doi:10.4018/IJICTE.2019070101

Bridges, B. K. (2008). Student support services: A practice brief based on BEAMS project outcomes. Institute for Higher Education Policy. Retrieved from http://www.ihep.org/research/publications/student-support-servicespractice-brief-based-beams-project-outcomes

Graham, C. (2006). Blended learning systems, definitions, current trends and future directions. In Handbook of blended learning: Global perspectives, local designs. John Wiley and Sons.

Gyamfi, S. A., \& Gyaase, P. O. (2015). Students' perception of blended learning environment: A case study of the University of Education, Winneba, Kumasi-Campus, Ghana. International Journal of Education and Development Using Information and Communication Technology, 11(1), 80-100.

ICT Deployment Committee Report. (2014). University of Ghana.

Krejcie, R. V., \& Morgan, D. W. (1970). Determining sample size for research activities. Educational and Psychological Measurement, 30(3), 607-610. doi:10.1177/001316447003000308

Kumar, V., \& Nanda, P. (2019). Social Media in Higher Education: A Framework for Continuous Engagement. International Journal of Information and Communication Technology Education, 15(1), 97-108. doi:10.4018/ IJICTE.2019010107

Lalima, K., \& Dangwal, L. (2017). Blended learning: An innovative approach. Universal Journal of Educational Research, 5(1), 129-136. doi:10.13189/ujer.2017.050116

Lin, W. S., \& Wang, C.-H. (2012). Antecedents to continued intention of adopting e-learning system in blended learning instruction: A contingency framework based on models of information system success and tasktechnology fit. Computer Education, 58(1), 88-99. doi:10.1016/j.compedu.2011.07.008

Lock, J., \& Johnson, C. (2016). Learning from transitioning to new technology that supports online and blended learning: A case study. In Proceedings of E-Learn: World Conference on E-Learning (pp. 184-192). Washington, DC: Association for the Advancement of Computing in Education (AACE). Retrieved from https://www. learntechlib.org/primary/p/173938/ 
Papadakis, S., Kalogiannakis, M., Sifaki, E., \& Vidakis, N. (2018). Access Moodle Using Smart Mobile Phones. A Case Study in a Greek University. In A. Brooks, E. Brooks, \& N. Vidakis (Eds.), Interactivity, Game Creation, Design, Learning, and Innovation. ArtsIT 2017, DLI 2017. Lecture Notes of the Institute for Computer Sciences, Social Informatics and Telecommunications Engineering (Vol. 229, pp. 376-385). Springer. doi:10.1007/9783-319-76908-0_36

Pokuaa, J. (2011). Blending the traditional face-to-face learning with instructional technology [Unpublished MPhil Thesis]. Kwame Nkrumah University of Science and Technology.

Rajkoomar, M., \& Raju, J. (2016). A Framework using blended learning for innovative teaching and learning. Journal of Educational Studies, 2(3), 1-9.

Sarfo, F. K., \& Ansong-Gyimah, K. (2010). The Perceptions of Students, Teachers and Educational Officers in Ghana on the Role of Computer and the Teacher in Promoting the First Five Principles of Instruction. The Turkish Online Journal of Educational Technology, 9(3), 85-95.

Simpson, O. (2016). Student support services for success in open and distance learning. A report in the Commonwealth Educational Media Centre for Asia (CEMCA). EdTech Notes.

Suorsa, J., \& Eskilsson, N. (2014). Students' perceptions of learning management systems. An explorative case study of upper secondary school students (Bachelor's thesis). Department of Applied Information Technology, University of Gothenburg, Sweden.

Suorsa, J., \& Eskilsson, N. (2014). Students' perceptions of learning management systems. An explorative case study of upper secondary school students (Bachelor's thesis). Department of Applied Information Technology, University of Gothenburg, Sweden.

Van Wyk, M. M. (2018). Economics student teachers' views on the usefulness of a flipped classroom pedagogical approach for an open distance eLearning environment. The International Journal of Information and Learning Technology, 35(4), 255-265. doi:10.1108/IJILT-07-2017-0068

Wu, J. H., Tennyson, R. D., \& Hsia, T. L. (2010). A study of student satisfaction in a blended e-learning system environment. Computers \& Education, 55(1), 155-164. doi:10.1016/j.compedu.2009.12.012

Zhonggen, Y. (2016). Blended learning over two decades. In Professional Development and Workplace Learning: Concepts, Methodologies, Tools, and Applications (pp. 1248-1267). IGI Global. doi:10.4018/978-1-4666-86328.ch068

Zhou, F., Zhao, C., Jiang, Z., \& Wang, L. (2017, June). A study on the learning support service of blended learning under the environment of online open courses. In 2017 International Symposium on Educational Technology (ISET) (pp. 272-276). IEEE. doi:10.1109/ISET.2017.67

\section{ENDNOTE}

The formula was $s=x 2 \mathrm{NP}(1-\mathrm{P})-\mathrm{d} 2(\mathrm{~N}-1)+\mathrm{x} 2 \mathrm{P}(1-\mathrm{P})$ 
Samuel Amponsah is a Senior Lecturer with a demonstrated history of working at all levels of education. He is the Acting Head of University of Ghana's Distance Education Department. He holds a Doctor of Education degree from the University of South Africa. Before joining the University of Ghana, Amponsah lectured at Esayidi TVET in South Africa and headed the Farming Management Department. Samuel's areas of research interest are distance and online learning and adult learning. He is a fellow of the Global Challenges Research Fund and currently on a departmental project investigating the adult learning needs of Ghanaian adult learners.

Yvette Ussher holds a doctoral degree in Sociology from the University of Stellenbosch, South Africa. She holds a Master of Philosophy degree (MPhil) in Sociology and a Bachelor of Arts degree in Sociology with Linguistics from the University of Ghana, Legon. She is currently a lecturer in the Department of Adult Education and Human Resource Studies of the School of Continuous and Distance Education, College of Education. She has been a visiting scholar/post- doctoral fellow of University of South Florida, USA. Her Research Interests include Information and Communication Technologies (ICTs), mobile communication, digital inequality, online learning, digital literacy, distance education, human resource development, and Informal economy.

Kwesi Amoak Benjamin holds a Master of Education Degree from the University of Ghana. He is a Documentation Specialist, ghostwriter, and journalist with expertise in Creative Education. Apart from The Unfinished Journey: Biography of V.C.R.A.C. Crabbe, he is also the author of The Creative One: Life and Works of Jake Otanka Obetsebi Lamptey, Quest for Excellence: Biographies of 15 Alumni of Legon, Arise Ghana Youth, Social Accountability through Active Citizenship: The Shama Model, and other publications. He has also ghostwritten more than ten books for clients in Ghana, Liberia, Togo, Nigeria and the United Kingdom (UK). Kwesi is the Executive Director of Mpuntusem Foundation, an NGO which focuses on the documentation of impact stories, relevant historical and cultural narratives. 